\section{Da Conexa ao Docpass: O Ambiente Competitivo das Plataformas de Telemedicina}

\author{
From Conexa to Docpass: The Competitive Environment of Telemedicine \\ Platforms
}

Disciplina: Estratégia e Inovação

Temática: Plataformas

Setor de atividade: Saúde

Região: Rio de Janeiro/Brasil

\section{INTRODUÇÃO}

Já era final da tarde de uma quinta-feira em junho de 2020, quando Fernando terminou a reunião por videoconferência com Guilherme Weigert, seu sócio. A Conexa Saúde era uma plataforma de telemedicina voltada ao segmento B2B (business to business) que atendia instituiçóes de saúde e empresas. Durante a pandemia do coronavírus (COVID-19), aproveitando a mudança da legislação, a Conexa lançou a plataforma de telemedicina Docpass, um spinoff da empresa voltado para o segmento B2C (business to consumers), que conectava médicos credenciados aos consumidores finais.

Aqueles meses de isolamento social por conta do COVID-19 não estavam sendo fáceis para Fernando Domingues, fundador e responsável pela parte comercial da Conexa Saúde. Há mais de um mês sem sair de casa, estava ansioso para retomar sua rotina agitada de jovem empreendedor. Fernando se orgulhava de ter fundado, juntamente com dois

1. Universidade Federal Fluminense, Faculdade de Administração e Ciências Contábeis, Departamento de Empreendedorismo, Niterói, RJ, Brasil.

2. Universidade Federal do Rio de Janeiro, Instituto COPPEAD de Administração, Rio de Janeiro, RJ, Brasil. 3. Pontifícia Universidade Católica do Rio de Janeiro, Rio de Janeiro, RJ, Brasil.

4. Fundação Getulio Vargas, Escola de Administração de Empresas de São Paulo, São Paulo, SP, Brasil.

Como citar: Moreira, C. S. da C., Freitas, F. D., Brandão, C., \& Araujo, C. A. S. (2021). Da Conexa ao Docpass: O ambiente competitivo das plataformas de telemedicina. Revista de Administração Contemporânea, 25 (spe). e200238. https://doi.org/10.1590/1982-7849rac2021 200238.por

\# de revisores convidados até a decisão:

$\stackrel{0}{0}_{0}^{0}$

sócios, "a maior plataforma independente de telemedicina da América Latina”.

Até o início de 2020, a Conexa só oferecia soluçóes de telemedicina no B2B, mas sempre almejara a entrada no B2C, chegando a criar, em 2019, uma plataforma pela qual o paciente poderia acessar os médicos, mas a iniciativa esbarrara na legislação. Entretanto, em abril de 2020, por conta do coronavírus, foi sancionada a lei que permitia a prática da telemedicina, enquanto a situaçáo de pandemia estivesse vigente, e a procura por teleatendimentos aumentou bastante, representando um forte indício de que havia potencial no B2C. Diante dessa oportunidade, os sócios criaram a Docpass. Em apenas três meses, o número de pacientes e de médicos cadastrados na plataforma cresceu vertiginosamente: de 100 mil para quatro milhóes de pacientes; e de três mil para mais de dez mil médicos.

Classificaçāo JEL: A20, I14, D12 Editor-chefe: Wesley Mendes-da-Silva (Fundação Getulio Vargas, EAESP, Brasil) Editora Associada: Paula C. P. de S. Chimenti (Universidade Federal do Rio de Janeiro, COPPEAD, Brasil) (t) Editor Convidado: Leonardo Marques (Universidade Federal do Rio de Janeiro, COPPEAD, Brasil) (c) Pareceristas: Lourival Chaves Júnior (Unidade de Ensino Superior do Sul do Maranhão, Brasil) (t) Adrian Kemmer Cernev (Fundação Getulio Vargas, EAESP, Brasill) Relatório de Revisão por Pares: O Relatório de Revisão por Pares está disponivel neste link externo. Recebido: $15 / 07 / 2020$ Última versão recebida em: 01/12/2020 Aceite em: 07/12/2020

$2+3-4$


Mas os sócios estavam cientes dos desafios que a nova plataforma representava. $\mathrm{Na}$ videoconferência, Fernando e Guilherme discutiram algumas questóes que os preocupavam: Como continuar crescendo diante do aumento da concorrência? Mais importante ainda: Como criar valor e fidelizar pacientes e médicos à Docpass, diante de uma ampla oferta de plataformas de telemedicina? Como existiam mais dúvidas que certezas naquele momento, decidiram fazer um levantamento detalhado de toda a situação e se reunir novamente em uma semana.

\section{HISTÓRICO DA CONEXA}

No início de 2017, a Conexa foi fundada com um conceito de clínica física. Situada no bairro de Copacabana, no Rio de Janeiro, a empresa recebia pessoalmente os pacientes para realizaçáo de atendimentos primários que, com o auxílio da telemedicina, podiam evoluir para consultas com especialistas. Os clínicos gerais exerciam suas atividades presencialmente e podiam entrar em contato com médicos especialistas, via telemedicina, para auxílio na condução dos casos dos pacientes. De acordo com Guilherme, "era uma clínica física empoderada pela telemedicina, com intuito de estabelecer uma jornada do paciente focada no seu médico generalista".

Só que esse modelo esbarrava na cultura do paciente de procurar um médico especialista. Além disso, existia a dificuldade de gerenciamento dos custos fixos. Entáo, no começo de 2018, os sócios decidiram implementar mudanças e se voltar para o que se tornou o coração do negócio: a atuação exclusiva em telemedicina. A clínica para atendimento presencial foi fechada e eles desenvolveram uma plataforma própria, que possibilitava realizar teleconsultas, conectando médicos e pacientes. Mas a clínica física tinha deixado um grande aprendizado: o paciente percebia grande valor quando, em um único ponto de contato, já conseguia resolver o problema todo. "O paciente saía com uma prescrição só, com uma solicitação de exames só. Isso, na cabeça dos pacientes, era uma percepção incrível. 'Poxa, eu nunca vi dois médicos falando do meu caso; nunca recebi só uma receita.' Esse era o ponto-chave" (Guilherme).

Esse aprendizado inspirou a soluçáo da telemedicina: como a plataforma tinha todo o histórico do paciente, quando o médico realizava um atendimento, tinha acesso aos prontuários anteriores e podia alterar, acrescentar e manter uma só receita.

Para crescer, a Conexa tinha contado com o investimento dos sócios e também de pessoas físicas e fundos. Posteriormente, a empresa fez uma captação financeira com um board médico, representado por profissionais renomados, dispostos a investir na plataforma e a apoiar o desenvolvimento do produto. Nesses anos de atuação, a Conexa conseguiu chamar a atenção de grandes grupos brasileiros, que se tornaram seus parceiros e clientes (Anexo 1). Até março de 2020, existiam dois tipos de ofertas B2B: (a) serviços de teleconsultas que as empresas clientes ofertavam como benefícios aos seus funcionários; e (b) assinatura que permitia às instituições de saúde usarem a plataforma de telemedicina (white label) para ofertarem seus serviços, utilizando suas próprias redes de médicos. Esse uso do software por assinatura é denominado software as a service (Saas).

$\mathrm{Na}$ modalidade de teleconsulta, grandes empresas disponibilizavam serviços de telemedicina para seus funcionários através da Conexa. Esses serviços podiam incluir, por exemplo, saúde ocupacional - como exames de admissão e demissão - e atendimentos primários, que serviam como uma triagem em casos de urgências ocorridas no ambiente de trabalho. As teleconsultas eram realizadas por médicos credenciados na rede da Conexa e podiam ocorrer tanto com hora marcada quanto em caráter de emergência. A precificação era per capita: a empresa pagava um valor fixo baixo por funcionário para ter direito ao atendimento, enquanto a Conexa controlava toda a gestão de atençáo primária da empresa por telemedicina por esse valor contratado. Apesar do valor fixo, a Conexa queria que seu serviço fosse bastante utilizado pela empresa contratante, para que esta percebesse valor no investimento. "Quando a gente entra em uma empresa, a gente faz uma campanha de marketing gigante, uma campanha de ativação. Começa a fazer mailing com os funcionários, entrando em contato com todos, falando que tem a telemedicina. Por que isso? Porque se a gente vende para a empresa a telemedicina e, se não tem uso, ela vai pagar por três meses e depois vai cancelar. Então, é muito melhor ser proativo do que reativo" (Fernando).

O modelo de negócios considerava também a atração e retenção da rede de médicos cadastrados. Eles trabalhavam em esquema de plantão e, para isso, a remuneração era equivalente à de um plantáo em um hospital particular. No início de 2020, a Conexa contava com cerca de três mil médicos cadastrados, que atendiam 100 mil pacientes. Existiam também situaçóes em que o modelo de negócios envolvia uma empresa de plano de saúde: "Nós temos uma grande empresa de varejo, cuja empresa do plano de saúde dos funcionários indica o uso da Conexa. Quem paga a Conexa é o varejista. O plano de saúde só é uma ponte, é um canal, náo tendo nenhuma relação direta com a Conexa" (Fernando).

$\mathrm{Na}$ modalidade Saas, a Conexa ofertava apenas o software em modalidade white label e o suporte técnico, permitindo à empresa cliente inserir sua identidade visual e fornecer teleconsultas utilizando sua rede própria de médicos credenciados. 


\section{A REGULAMENTAÇÃO DA TELEMEDICINA NO BRASIL E OS IMPACTOS DO COVID-19}

A telemedicina já fazia parte da realidade brasileira há algum tempo, porém permanecia sendo motivo de debates e controvérsias. Em 2002, o Conselho Federal de Medicina (CFM) passou a resolução CFM n. ${ }^{\circ} 1.643 / 2002^{1}$ para definir e disciplinar a prestação de serviços através da telemedicina. Entretanto, com a evolução tecnológica e as transformaçōes nas práticas de medicina, muitos conceitos e formas de ação ficaram desregulamentados. Para preencher essa lacuna e deixar o ambiente legal mais claro, no início de fevereiro de 2019, o CFM anunciou a publicação da resolução CFM n. ${ }^{\circ} 2.227 / 2018^{2}$, que também tinha como objetivo detalhar e definir as atividades relacionadas à telemedicina. A questão, porém, estava longe de ser resolvida. Logo que o CFM publicou essa resoluçáo, parte da comunidade médica e entidades de classe manifestaram ao CFM sua resistência. Assim, no dia 22 de fevereiro de 2019, a resolução foi revogada pelo Conselho ${ }^{3}$.

Entretanto, o que ninguém esperava é que um ano depois o cenário mudaria drasticamente: o COVID-19 chegou ao Brasil em fevereiro de 2020, demandando uma resposta rápida quanto à regulamentação da telemedicina. Assim, em 15 de abril de 2020, a lei n. ${ }^{\circ} 13.989$ foi sancionada, autorizando a prática da telemedicina durante a pandemia ${ }^{4}$. Através do atendimento a distância, pacientes passaram a poder se conectar com médicos de maneira segura, proporcionando vários benefícios, como acompanhamento de pacientes crônicos, realizaçáo de cuidados primários, resolução de dúvidas e diminuição de idas às emergências, que representavam um risco de contaminaçáo para o paciente e uma sobrecarga para o sistema de saúde.

Assim, a regulamentação se tornou uma oportunidade para as empresas que, como a Conexa, já se inseriam no contexto da telessaúde. Porém, dado que a lei era válida somente durante a pandemia de COVID-19, náo havia garantia da legalidade da telemedicina no futuro.

\section{A DOCPASS, UMA OFERTA B2C}

Tão logo a lei n. ${ }^{\circ} 13.989$ foi sancionada, os sócios da Conexa decidiram aproveitar aquela oportunidade. Com mais investimento, seria possível dar acesso a $75 \%$ da população que não tinha plano de saúde e que tinha dificuldade de ter um atendimento médico bom. "A aprovação da telemedicina direto para o paciente abriu o mercado de 150 milhóes de usuários que não têm plano de saúde hoje. A gente quer também atuar na esfera de quem não tem plano de saúde e precisa do acesso médico" (Fernando).
Mas aquela não foi a primeira vez que eles haviam pensado em entrar no modelo B2C. Em 2019, com a primeira tentativa de liberação da telemedicina, investimentos foram feitos para a criação da nova solução, mas a legislação foi revogada e os sócios deram um passo atrás e decidiram se preparar melhor, desenvolver mais o produto. Assim, com a regulamentaçáo em 2020, a plataforma já estava pronta para lançar a Docpass. "A gente começou a ver uma curva de utilização muito grande na plataforma. A gente passou, em poucos dias, de 40-50 atendimentos para 2.000 atendimentos por dia. Aí, nesse crescimento a gente falou: agora é a hora. A plataforma está pronta. A gente está conseguindo suportar, não saiu do ar, está tudo bem, então agora é hora de ir para o mercado do B2C" (Guilherme).

A Docpass foi criada para garantir o foco de toda a equipe no público B2C. "Não dá para a gente ter uma equipe única olhando para o B2B e B2C. São mercados diferentes, é tudo diferente" (Fernando).

Além disso, havia a preocupação de não criar ruído com os clientes B2B. "A gente teve muita discussão sobre isso, porque fazia sentido [manter a Conexa], do ponto de vista de sinergia, mas existiam os riscos de conflitos. A gente quis blindar esse potencial problema. A gente não confundiu o usuário e nem atraiu o cliente do B2B para nossa marca B2C" (Guilherme).

As duas empresas - Conexa e Docpass - aproveitavam algumas sinergias, como o desenvolvimento da plataforma, o jurídico e o backoffice. Contudo, os times eram diferentes para áreas mais específicas, como comunicação, marketing, aquisição do cliente e comercial.

Os sócios sabiam que precisariam desenvolver toda uma nova abordagem de comunicação para atrair os pacientes e que precisariam ampliar o número de médicos de plantão. Mas o COVID-19 não tinha somente possibilitado a mudança da legislação: ele tinha também reduzido uma barreira cultural quanto à utilização da telemedicina. Para os pacientes, a telemedicina se mostrava um caminho mais seguro, reduzindo as chances de contágio; para os médicos, o atendimento remoto trazia segurança e representava uma forma de manter suas atividades profissionais e cuidar dos pacientes.

Um grande desafio foi preparar a nova plataforma para os meios de pagamento, que no $\mathrm{B} 2 \mathrm{~B}$ não existiam. Foram necessárias três semanas de investimentos na tecnologia para liberar a funcionalidade de pagamento de cartáo. Outro desafio era definir a proposta de valor para o paciente e qual seria o target. Náo havia tempo para fazer pesquisa. A solução foi colocar a plataforma no ar e ir testando. Foram feitos testes com público $\mathrm{B}+\mathrm{e}$, em seguida, C. Tudo de forma digital, com o time de growth dedicado, que fazia teste $A / B$, teste de campanha, de sensibilidade. Para 
aprimorar o produto, eram feitas entrevistas com pacientes que utilizavam a plataforma e com aqueles que entravam e não faziam consulta.

Havia ainda o desafio de trazer novos médicos, dado que o potencial de atendimentos cresceria muito com a nova empresa. Os médicos que já atendiam no B2B foram "plugados" na nova plataforma. Além disso, foram feitas campanhas de divulgação via sociedades médicas e operadoras de saúde. Com isso, rapidamente a nova plataforma estava povoada de médicos. Só que também era preciso atrair pacientes: "No $\mathrm{B} 2 \mathrm{C}$, a gente é muito agressivo com marketing digital, porque é o marketing direto com o paciente; entáo, eu estou falando de Google e muito conteúdo. A gente montou um blog para falar de telemedicina, a gente faz lives no Instagram... então, é um marketing mais específico" (Fernando).

A Docpass utilizava canais virtuais para se comunicar com o público e também parcerias com outras empresas. $\mathrm{O}$ principal parceiro era a Droga Raia, que montou um site para o COVID-19 e chamou cinco empresas de telemedicina para participar, sendo a Conexa/Docpass uma delas. Portanto, duas estratégias foram utilizadas: uma de growth interna, muito focada no digital, com custo de aquisição de cliente, lifetime e campanhas bem direcionadas; e outra que olhava os canais de massificação segmentada, como farmácias, plataformas de e-commerce, de delivery e bancos.

Para pacientes e médicos aderirem, bastava baixar o aplicativo e inserir seus dados. O paciente, com isso, já estava ativo na plataforma. Os médicos, entretanto, ainda passavam por um processo de validaçáo do cadastro, que demorava tipicamente cinco dias. Eram avaliados CRM, currículo, diploma, especialidade e experiência do médico, de forma similar ao que ocorre em um plantão tradicional. Em seguida, havia um processo de entrevista e um pequeno treinamento. Só então o profissional estaria apto. $\mathrm{Na}$ plataforma, o paciente podia escolher um dos médicos cadastrados, avaliando seu currículo, o CRM, a especialidade e a nota média recebida pelo profissional nos atendimentos anteriores. Além da teleconsulta, que poderia ocorrer via videoconferência, chat ou chamada de voz, a plataforma oferecia prescrição eletrônica de medicamentos e exames.

Uma teleconsulta pelo Docpass custava $\mathrm{R} \$ 100,00$. Desse valor, $20 \%$ ficava para a plataforma e $80 \%$ para o médico - modelo de divisão similar a outras plataformas que já se consolidaram no mercado. Nos meses iniciais da atuação B2C, a fim de expandir sua rede de pacientes mais rapidamente, a Docpass ofereceu um desconto de $\mathrm{R} \$$ 50,00 , sem alterar a remuneraçáo dos médicos. Como a rede de médicos credenciados da Docpass é a mesma da oferta B2B, entrar no mercado B2C acabou por ajudar a otimizar a capacidade de atendimento dos plantóes. Tipicamente, os médicos que aderiam à plataforma eram jovens recém- formados. As especialidades médicas mais procuradas na Docpass eram clínica geral, dermatologia e psiquiatria. Especialidades dependentes de exame clínico mais minucioso não eram oferecidas.

A plataforma permitia o registro do prontuário do paciente e este tinha acesso ao seu histórico. Os dados dos pacientes não eram monetizados. Fernando ponderava que o histórico do prontuário representaria um custo de mudança para o paciente: "uma vez que um paciente tivesse um prontuário detalhado em uma plataforma, poderia hesitar em trocar de plataforma”. Mas os sócios sabiam que a barreira de saída mais forte seria a experiência e o relacionamento com os pacientes. Para o paciente escolher a Docpass, era preciso ter uma experiência fácil, intuitiva, e ter médicos de qualidade. "Foco na qualidade do atendimento. Um atendimento que não tenha falta. Um atendimento 24 horas em que ele aguarde o menor tempo possível. São coisas do produto que vão favorecer. E tem a marca. Depois que a gente fortalecer essa marca e posicioná-la como uma marca que está inovando, que está pensando em um atendimento muito bom para esse usuário, ele vai começar a se fidelizar" (Guilherme).

A proposta de valor ia sendo aprimorada ao longo do tempo. "Pegamos todas as propostas de valores que seriam realmente endereçadas para esse público e começamos a oferecer. A gente viu que eles [pacientes] queriam especialidade; colocamos especialidade. Depois, saúde mental; incorporamos saúde mental. E agora estamos fazendo testes de engajamento, utilizando campanhas de post notification, para ver se ele volta para a plataforma. São formas que a gente tem hoje para engajar o usuário. E parcerias. Desconto em farmácias, desconto em exames. Começar a trazer agregados para dentro do nosso produto" (Guilherme).

Além disso, para assegurar qualidade no atendimento, a empresa focava em três pilares: curadoria; Net Promoter Score (NPS); e protocolos. A curadoria, através da análise de currículo, ficava responsável por garantir que a plataforma contasse com bons médicos. O NPS era o instrumento utilizado pelos pacientes para avaliar a plataforma e o médico após a consulta, gerando uma nota média que ficava atrelada ao perfil do profissional. Havia ainda espaço para sugestóes de melhorias. Quando um atendimento recebia nota ruim, buscava-se localizar e conversar com o usuário para entender o motivo. Cada caso era enquadrado em categorias: quando era uma falha do sistema ou do médico, havia uma intervenção mais peculiar do que quando era um problema de conexão do paciente, por exemplo. Uma barreira enfrentada pelos pacientes da classe $C$ era a má qualidade do acesso à internet, prejudicando a experiência da teleconsulta. O terceiro pilar eram os protocolos, oferecidos 
pela Docpass para auxiliar os médicos na tomada de decisão e garantir a qualidade dos atendimentos.

Os sócios entendiam que precisavam acelerar ainda mais o crescimento. Uma das ideias era associar-se a plataformas de outros setores, como Rappi, Americanas e Magalu, para que elas pudessem ofertar telemedicina no seu portfólio.

\section{O AMBIENTE COMPETITIVO}

Um novo ambiente competitivo se formou com a liberação da telemedicina. Assim, a Conexa se insere em um ambiente competitivo, complexo, marcado pela presença de 'organizaçōes' que possuem diferentes características. Algumas delas já atuavam no ramo da telemedicina antes do COVID-19, como a concorrente global Teladoc; outras foram impulsionados pela crise a se posicionar mais fortemente no mercado e a entrar no setor de telemedicina, como a Dr. Consulta. Alguns dos principais competidores podem ser destacados:

Teladoc Health: multinacional considerada líder global em atendimento virtual, foi criada em 2002, nos Estados Unidos. Está presente em diversos países, como China, Austrália, Canadá, França, Reino Unido, Espanha, Portugal e Hungria. Com a pandemia, a procura por suas consultas duplicou, chegando a mais de 20 mil consultas por $\mathrm{dia}^{5}$, e apresentou um resultado maior do que o esperado em suas receitas para o primeiro trimestre de 2020. No início de 2020, a empresa chegou ao Brasil e lançou o Teladoc App para condução direta de telemedicina com pacientes.

Docway: fundada em 2015, em Curitiba, a Docway é uma empresa que já vem crescendo há um tempo no setor, com inovaçóes na saúde. Inicialmente voltada para ser uma plataforma que conecta médicos e pacientes para atendimentos domiciliares personalizados, em 2018 a empresa passou a oferecer atividades de telemedicina como complemento ao seu serviço principal. $\mathrm{O}$ seu modelo de negócios possibilita que pacientes escolham seus médicos, de acordo com a especialidade desejada, e combinem o local de atendimento, podendo ser em sua residência ou outra localização. É voltado especialmente para casos de baixa complexidade e não há atendimento emergencial. A empresa oferta serviços tanto no B2B, tendo relaçóes com seguradoras, quanto no B2C. O aplicativo da Docway abrange mais de 250 cidades brasileiras. Para lidar com a pandemia, a empresa inseriu os serviços de teleorientação, junto aos planos de saúde, para evitar idas ao pronto socorro e exposição ao novo vírus.

Dr. Consulta: considerada a maior healthtech brasileira e ganhadora de prêmio internacional de empreendedorismo social, é uma rede física de centros médicos, que fornece atendimento de clínica geral e especialidades médicas, dentistas, realização de exames e pequenas cirurgias. Foi criada em 2011, em Heliópolis, na Zona Sul de São Paulo. Em 2020, encontrava-se presente em São Paulo, Rio de Janeiro e Minas Gerais. Seu posicionamento é de ter impacto social e aumentar o acesso à saúde entre a populaçáo, principalmente para pessoas sem plano de saúde. O COVID-19 impulsionou a empresa a entrar na telemedicina, sendo lançado o Dr. Consulta Online, seu serviço de telemedicina que usa os próprios médicos da rede física para realizar teleconsultas agendadas on-line, com preços mais baratos do que os das consultas presenciais e variando de acordo com a especialidade médica desejada.

Além disso, grandes empresas do setor de saúde brasileiro, como seguradoras, hospitais e empresas de medicina diagnóstica vêm se movimentando na direção de incluir o atendimento a distância em suas ofertas. $\mathrm{O}$ Hospital Israelita Albert Einstein já usava a telemedicina para realização de consultas e teleinterconsultas entre médicos antes mesmo da pandemia. O Grupo Fleury de medicina diagnóstica, com o isolamento social, lançou a plataforma Cuidar Digital para realização de teleconsultas, que conta com prontuário eletrônico e acesso a exames das marcas do grupo. Já a Dasa, também da área de diagnóstico, criou uma plataforma de conscientizaçáo sobre o COVID-19 e abriu frentes de atendimento médico por telemedicina.

Com relação à concorrência, Fernando reforçava o pioneirismo do Conexa/Docpass na telemedicina no Brasil como um grande diferencial. "A gente está há mais tempo investindo na plataforma, na experiência do paciente, na experiência do médico. A gente hoje, por estar há mais tempo, tem um produto melhor. A gente está com o NPS de $87 \%$. Podemos explicar esse NPS altíssimo pelo fato de a gente já ter errado, já ter pivotado e hoje carregar uma bagagem. Já que a gente foi a primeira plataforma independente de telemedicina no Brasil" (Fernando).

Guilherme fazia questáo de reforçar que a concorrência aumentaria muito: "Eu não acho que é um espaço para um só player, porque o mercado é muito grande. E vai estar muito segmentado. Você vai ter plataformas que vão ser superboas em saúde mental, você vai ter algumas que são para diabetes. Nós queremos ser mais abrangentes, através de parcerias ou de aquisiçóes, para conseguir, de fato, ter a maior parte desse mercado" (Guilherme).

\section{COMO FICA O CENÁRIO PÓS-COVID-19?}

Fernando havia se preparado para uma nova videoconferência com Guilherme e começou falando da sua crença no potencial da telemedicina. Em poucos meses, a Conexa tinha saído dos modelos mediados por empresas e estava fornecendo serviço direto para o paciente. Ainda 
havia muito pela frente. "A gente acha que o mercado vai continuar em franca expansão no pós-COVID, porque a telemedicina aqui no Brasil ainda não é nem 1\% explorada quando você compara com os Estados Unidos que já é um mercado já muito mais avançado. Então, pelo menos nos próximos cinco anos, a gente vai ver aí o crescimento muito exponencial de todo mundo, de todos os parceiros" (Fernando).

Mas tinha uma coisa que preocupava muito Fernando. Como ficaria a regulamentação quando a pandemia acabasse? "Hoje um desafio para a gente é a parte legal. A gente espera que a telemedicina possa continuar valendo. Mas existe esse risco jurídico. A qualquer momento o CFM pode de novo embarreirar a telemedicina" (Fernando).

Guilherme acreditava que o futuro viria da ciência. "Um ponto muito importante é com a ciência. A gente tem se preocupado muito com a ciência na telemedicina. Em trazer dados, estruturar dados para a gente conseguir provar que a telemedicina é, de fato, positiva, que é segura. $\mathrm{O}$ médico acredita muito na medicina baseada na evidência. Então, se a gente não trouxer isso para a mesa, vai estar sempre lutando com 'o que eu acho' e não com o que é. Então essa é uma preocupaçáo grande, e a gente tem conversado com os nossos concorrentes, com os nossos parceiros, para a ciência vir de uma forma mais robusta" (Guilherme).

Mesmo com essas preocupaçóes, eles concordavam que não era hora de diminuir o ímpeto da Conexa se quisessem continuar a se posicionar "como a maior plataforma independente de telemedicina da América Latina”. Como toda plataforma, eles precisavam expandir a base de usuários. Como fariam isso? Como ficaria a questão da concorrência e das parcerias após a pandemia? Como criar mais valor para a plataforma? O brainstorming estava apenas começando.

\section{NOTAS}

1. Resolução CFM n. 1.643/2020. (2020). Define e disciplina a prestação de serviços através da Telemedicina. Retrieved from https://sistemas.cfm.org.br/normas/visualizar/ resolucoes/BR/2002/1643

2. Resolução CFM n. 2.227/2018. Revogada. (2019). Define e disciplina a telemedicina como forma de prestação de serviços médicos mediados por tecnologias. Retrieved from https://sistemas.cfm.org.br/normas/visualizar/resolucoes/ $\mathrm{BR} / 2018 / 2227$

3. Conselho Federal de Medicina. (2019). Retrieved from https://portal.cfm.org.br/index.php?option $=$ com content \&view=article\&id=28096:2019-02-22-15-13-20\&catid=3

4. Lei n. 13.989 de 15 de abril de 2020. (2020). Dispóe sobre o uso da telemedicina durante a crise causada pelo coronavírus (SARS-CoV-2). Retrieved from http://www. in.gov.br/en/web/dou/-/lei-n-13.989-de-15-de-abrilde-2020-252726328

5. Krouse, S. (2020). Teladoc's remote doctor visits surge in Coronavirus crisis. The Wall Street Journal. Retrieved from https://www.wsj.com/articles/teladocs-remote-doctorvisits-surge-in-coronavirus-crisis-11586894400? $\mathrm{mod}=$ searc $\underline{\text { hresults\&page }=1 \& \text { pos }=3}$ 


\section{ANEXO 1}

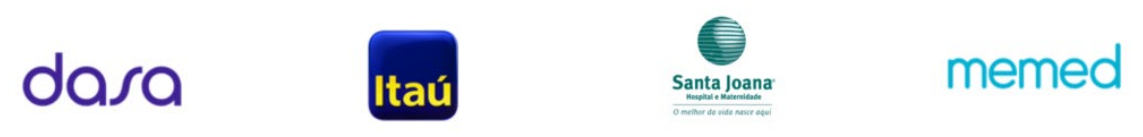

CacauShow
Mfresp

\section{SEG YMEDIC}

Figura A1. Clientes da Conexa. 


\section{RESUMO}

O caso narra a trajetória de uma plataforma de telemedicina no Brasil. A Conexa, uma empresa que já operava com modelo B2B com telemedicina, aproveitou a mudança de regulamentação durante a pandemia do coronavírus (COVID-19) e lançou a Docpass, uma plataforma B2C. A pandemia não trouxe somente a mudança na legislação, como também propiciou um contexto que reduziu as barreiras culturais para a adoção de tal serviço tanto para médicos quanto para pacientes. $O$ caso é recomendado para disciplinas de Estratégia e Inovação, mais especificamente em sessóes dedicadas aos modelos de negócios baseados em plataformas, quando forem trabalhados os seguintes objetivos de aprendizagem: (a) diagnóstico sobre desdobramentos do COVID-19 em um negócio de telemedicina comparando-se o antes, o durante e o depois; (b) compreensão dos efeitos de rede presentes nas plataformas e seus reflexos em termos de valor; (c) compreensão da dinâmica competitiva em um ecossistema de plataforma.

Palavras-chave: plataforma; efeitos de rede; coopetição; telemedicina.

\section{Objetivos didáticos}

Este caso de ensino foi elaborado para uso em cursos de graduação, extensão ou pós-graduação (lato e stricto sensu) em Administraçáo e pode ser empregado em disciplinas relacionadas a estratégia e inovação, mais especificamente em sessóes dedicadas aos modelos de negócios baseados em plataformas. Também pode ser utilizado em cursos de Gestão de Serviços de Saúde, em sessão sobre inovação. Ao final da discussão do caso, espera-se que os alunos alcancem os seguintes aprendizados: (a) diagnóstico sobre desdobramentos do COVID-19 em um negócio de telemedicina comparando-se o antes, o durante e o depois; (b) compreensão dos efeitos de rede presentes nas plataformas e seus reflexos em termos de valor; (c) compreensáo da dinâmica competitiva em um ecossistema de plataforma.

Ao construirmos esta nota de ensino, optamos por um recorte que enfoca os conceitos de efeitos de rede e coopetiçáo. No entanto, o caso permite outros ângulos de análise e caminhos de discussão, que registramos aqui com a respectiva indicação de literatura para que o docente possa avaliar de acordo com suas preferências: gestão de plataformas digitais (Tiwana, 2013); mercado de dois lados e/ou de múltiplos lados (Hagiu, 2014); e aprisionamento e custo de troca (Shapiro \& Varian, 2003).

\section{ABSTRACT}

The case reports the trajectory of a telemedicine platform in Brazil. Conexa, a company that already operated with a telemedicine B2B model, took advantage of the regulatory change during the coronavirus pandemic (COVID-19) and launched Docpass, a B2C platform. The pandemic not only brought about a change in legislation, but also provided a context that reduced cultural barriers to the adoption of such a service for both doctors and patients. The case is recommended for Strategy and Innovation disciplines, more specifically in sessions dedicated to business models based on platforms, when the following learning objectives are worked on: (a) diagnosis of COVID-19 effects in a telemedicine business by comparing before, during, and after the pandemic; (b) understanding the network effects present on the platforms and their reflections in terms of value; (c) understanding the competitive dynamics in a platform ecosystem.

Keywords: platform; network effects; coopetition; telemedicine.

\section{Protagonista e fontes de informação}

O caso é apresentado do ponto de vista de dois protagonistas, Fernando Domingues e Guilherme Weigert, sócios na Conexa, plataforma brasileira de telemedicina. Foram realizadas entrevistas em profundidade semiestruturadas com ambos os sócios, com duração de uma hora cada. Também foram utilizadas fontes secundárias, como leis federais, regulamentaçóes do Conselho Federal de Medicina, websites e reportagens.

\section{Plano de ensino}

O caso pode ser utilizado com ou sem indicação de leitura prévia, conforme preferência do docente. Caso o professor opte por não indicar leitura prévia, pode orientar os alunos para que pesquisem os conceitos sobre os quais não tiverem familiaridade durante a leitura do caso. Nesse contexto, recomenda-se que, durante a discussáo, o professor aprofunde conceitos como: B2B, B2C, Saas e outros, conforme forem emergindo. Por outro lado, se o professor preferir indicar leituras prévias, que familiarizem o aluno com os conceitos relacionados ao modelo de negócios baseado em plataformas, pode-se sugerir a leitura dos capítulos 2 e 10 do livro Plataforma: a revolução da estratégia, de Parker, Van Alstyne e Choudary (2018). 
O caso foi desenvolvido pressupondo a preparação extraclasse individual prévia dos alunos.

Estimamos o tempo total para a sessão de discussão do caso em 120 minutos, buscando adequar a discussão à duração típica das aulas. No entanto, o professor pode optar por uma discussão mais alongada se houver mais tempo disponível. Os primeiros 20 minutos seriam dedicados à discussáo em pequenos grupos. A discussão plenária pode variar entre $80 \mathrm{e}$ 100 minutos, dependendo da distribuição típica de horários de aula. A abertura da discussão em plenário - Lâmina 1 do quadro proposto (ver Apêndice) - deve exigir 10-15 minutos. A análise das questóes do caso - Lâminas 1 a 5 do quadro proposto (ver Apêndice) - deve consumir 60-75 minutos. $\mathrm{O}$ encerramento da discussão plenária ocupará os 10 minutos restantes.

\section{Questões para discussão}

Apresentamos um conjunto de questóes (discussion questions) que poderiam ser usadas para estimular a análise do caso em plenária:

1. Como a Conexa enxergava e atuava no cenário da telemedicina no Brasil antes da pandemia?

2. Como a Conexa reage à regulamentação da telemedicina ocorrida durante a pandemia?

3. Quais são os desafios pós-COVID em relação ao ambiente competitivo da telemedicina no Brasil?

\section{Análise do caso em plenária}

\section{Abertura da discussão do caso em plenária}

A abertura da discussão pode ser usada para explorar como era o cenário da telemedicina no Brasil antes do COVID-19. Para tanto, o professor pode perguntar: "Como podemos caracterizar o cenário da telemedicina no Brasil antes da pandemia?" As respostas dos alunos podem suscitar aspectos como:

- Tecnologia necessária para telemedicina já estava disponível (+).

- Barreira cultural - desconfiança em relação à telemedicina (-).

- Barreira educacional - falta de capacitação tecnológica dos usuários (-). Porém, pacientes e médicos mais novos já estavam mais familiarizados com a tecnologia. $(+)$.

- Tentativa de regulamentação da telemedicina em 2019 falha por resistência e protestos da classe médica (-).
O professor pode listar os tópicos levantados pelos alunos para o início da construção de um quadro comparativo, que estará completo ao final da discussão - ver Lâmina 1 do plano de discussão plenária (Apêndice).

\section{Respostas às questões para discussão com suporte da literatura}

Questão 1: Como a Conexa enxergava e atuava no cenário da telemedicina no Brasil antes da pandemia?

O objetivo dessa questão é mapear os impactos do COVID-19 no modelo de negócio de uma empresa de plataforma, levando em consideração o cenário competitivo em que ela estava inserida. Para tanto, o professor pode fazer as seguintes transition questions (TQ):

TQ 1.1: Como a plataforma Conexa vinha atuando antes da pandemia?

Com as informaçóes descritas no caso, os alunos podem descrever as modalidades de oferta B2B da Conexa (Saas e teleconsulta), mostrando os lados conectados por meio da plataforma. Essa pergunta traz a oportunidade de o docente desenhar o ecossistema envolvido na plataforma Conexa a partir das contribuiçóes dos alunos - ver Lâmina 1 do plano de discussão plenária (Apêndice).

Com o desenho do B2B completo, o professor pode fazer provocaçóes para que, indutivamente, os alunos possam refletir sobre o conceito de plataforma.

Plataformas são "um novo modelo de negócios que usa a tecnologia para conectar pessoas, organizaçóes e recursos em um ecossistema interativo, no qual podem ser criadas e trocadas quantidades incríveis de valor" (Parker, Van Alstyne, \& Choudary, 2018, p. 11). Plataformas obtêm vantagens econômicas decorrentes de ambientes digitais (McAfee \& Brynjolfsson, 2017) ao viabilizar e facilitar a conexão e a criação de valor entre usuários que passam a trocar bens, serviços, informaçōes, ideias e outros valores intangíveis e sociais (Parker et al., 2018). Caso os alunos não estejam familiarizados com o conceito de plataforma, o docente pode fazer comparaçóes com outras plataformas, tais como: Uber, Airbnb, Marketplace da Amazon e Facebook.

TQ 1.2: Pensando na oferta de Saas, quais lados a plataforma está conectando? Como gera valor para esses lados?

$\mathrm{Na}$ oferta Saas, a Conexa (C) oferecia os recursos tecnológicos para que instituiçõos do sistema de saúde (IS), tais como seguradoras, hospitais e empresas de diagnóstico, pudessem oferecer aos seus pacientes $(\mathrm{P})$ os serviços de telemedicina a partir da sua rede de médicos $(\mathrm{M})$. A Conexa obtinha lucros a partir de seu software. As instituiçóes complementavam seu portfólio de ofertas sem precisar se desviar de seu foco em serviços de saúde para desenvolver 
os softwares necessários. Por outro lado, os clientes dessas empresas podiam optar pela telemedicina e tratar seus problemas de saúde de forma mais conveniente e rápida, muitas vezes evitando, por exemplo, um agravamento do quadro ou uma ida à emergência (e, portanto, potencialmente reduzindo os custos da seguradora).

TQ 1.3: E agora, pensando na oferta de serviços B2B, quais lados a plataforma está conectando? Como gera valor para esses lados?

$\mathrm{Na}$ oferta de serviços B2B, a Conexa era contratada por grandes empresas $(\mathrm{E})$ e conectava uma rede de médicos credenciados $(\mathrm{M})$ aos funcionários destas $(\mathrm{P})$, oferecendo teleconsultas e teleatendimentos. Nesse modelo, a Conexa gerenciava sua carteira de clientes e a prestaçáo dos serviços de forma lucrativa. As empresas podiam oferecer aos seus funcionários cuidados de saúde como um benefício, possibilitando maior conveniência e aumentando sua satisfação, ao mesmo tempo que reduziam faltas, evitavam custos maiores e melhoravam sua imagem.

TQ 1.4: Antes da pandemia, como era a visão da Conexa em relação à telemedicina $\mathrm{B} 2 \mathrm{C}$ ?

O caso mostra que a liderança da Conexa já havia construído uma visão de atuar no mercado B2C, aproveitando toda a trajetória de aprendizados vivenciados no B2B. A empresa identificou a oportunidade do B2C mesmo antes da regulamentação do setor. Seguindo essa visão, já prepararam o terreno para o B2C assim que a principal barreira - a legal fosse desfeita. A liderança teve um papel central na capacidade inovadora da empresa, uma vez que, além de gerenciar o negócio B2B para aumentar sua eficiência, pôde antever oportunidades, fortalecendo e disseminando a visão de modo a suportar também a inovação.

TQ 1.5: Como a chegada da pandemia altera o contexto da telemedicina?

O professor pode listar os tópicos levantados pelos alunos para complementar o quadro comparativo iniciado na abertura da discussão - ver Lâminas 2 e 3 do plano de discussão plenária (Apêndice).

- O cuidado remoto oferecia vantagens por tratar-se de doença infectocontagiosa $(+)$.

- Com o distanciamento social, pacientes com outras doenças também valorizaram o cuidado remoto por não desejarem se expor aos riscos (+).

- Serviços de saúde apresentavam demandas acima de sua capacidade, fazendo com que cuidados remotos fossem também valorizados $(+)$.

- Médicos precisavam criar formas de cuidar de seus pacientes e, ao mesmo tempo, gerar receitas. Muitos passaram a valorizar o atendimento virtual $(+)$.
- Lei e regulamentação da telemedicina ocorrem durante a pandemia $(+)$.

- Planos de saúde passaram a remunerar teleatendimento $(+)$.

- Médicos e população em geral, pressionados pela situação, precisaram aprender e ter contato com plataformas de reunião, e-commerce e outras tecnologias de informação e comunicação, adquirindo competências e desmistificando seu uso (+).

- Algumas especialidades conseguiram se beneficiar da regulamentação de forma imediata (+), outras ainda se encontravam limitadas pelas características dos exames físicos necessários (-).

- Empresas colocando rapidamente suas soluçóes de telemedicina no mercado com diferentes graus de maturidade. Foram aprendendo durante o processo (+-).

Os aspectos mencionados mostram que o cenário pandêmico foi favorável à aceleraçáo da implantação da telemedicina no país, derrubando barreiras legais, culturais, educacionais e econômicas e abrindo novas oportunidades de criação de valor.

Questáo 2: Como a Conexa reage à regulamentaçáo da telemedicina ocorrida durante a pandemia?

Essa pergunta permite detalhar a oferta B2C e a nova marca criada Docpass, com o objetivo de explorar a compreensão dos efeitos de rede presentes nas plataformas e seus reflexos em termos de valor nos modelos de negócios de plataformas.

Sugere-se que o professor volte ao desenho do ecossistema para que possa complementá-lo com as contribuiçóes dos alunos.

A entrada da Conexa em um novo mercado pode ser um bom contexto para explorar o conceito de efeitos de rede e seus desdobramentos com relação à criação de valor. Na lógica do mercado de plataformas, a comunidade de usuários pode impactar, tanto positiva quanto negativamente, a capacidade da plataforma em gerar valor. Nesse sentido, "efeitos de rede positivos são a principal fonte de criação de valor e de vantagem competitiva numa plataforma de negócio" (Parker et al., 2018, p. 27).

TQ 2.1: Como a plataforma gera valor para médicos e pacientes no $\mathrm{B} 2 \mathrm{C}$ ?

Os alunos possivelmente colocariam que os pacientes poderiam obter valor conseguindo ser atendidos rapidamente, por uma rede ampla de bons profissionais, com conveniência e qualidade, de modo que solucionem suas demandas de forma satisfatória e pagando um preço justo. 
Analisando o lado dos médicos, os alunos poderiam mencionar que os profissionais obteriam valor por meio da atração de novos pacientes, maior volume de atendimentos, uma maior remuneração total (muitas vezes a telemedicina representa uma fonte de receita complementar às tradicionais), além de uma experiência de trabalho facilitada, conveniente e com uma infraestrutura de qualidade (Figura 1).
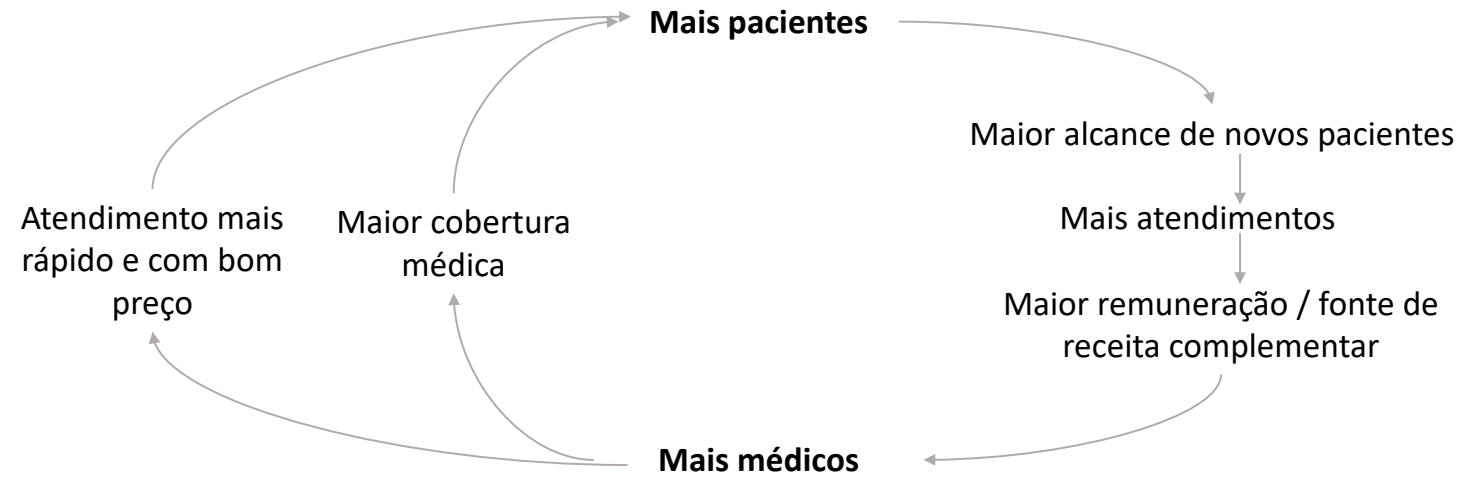

Figura 1. Efeitos de rede Docpass.

TQ 2.2: Olhando para os dois lados da rede, como um lado impacta a criação de valor do outro? Esses impactos são positivos ou negativos?

A ideia aqui é mostrar os efeitos de rede, ou seja, quando o crescimento de um lado da rede pode impactar o valor para o outro. Um exemplo opcional que o docente pode utilizar para comparar e sedimentar o entendimento de efeitos de rede é o Uber.

Exemplo: A plataforma do Uber faz o pareamento entre passageiros que precisam se deslocar e motoristas que querem prestar serviço para obter receita. $\mathrm{O}$ que acontece com os passageiros se o Uber começa a atuar em uma nova cidade e ainda possui poucos motoristas cadastrados? (Os passageiros ficarão insatisfeitos, pois teráo alto tempo de espera e pouca conveniência. Provavelmente, ainda falarão mal do serviço para seus conhecidos). E, por outro lado, o que acontece com os motoristas dessa mesma cidade se o Uber ainda possuir poucos passageiros utilizando o serviço? (Esses motoristas também ficarão insatisfeitos, com muito tempo ocioso e baixo faturamento. Provavelmente, também irão desencorajar outros colegas a se credenciarem). Nesse contexto, é necessário que o Uber se preocupe com o crescimento das duas redes de motoristas e passageiros - para criar mais valor para seus usuários e produzir um ciclo virtuoso com precificação atraente e um boca a boca positivo. Os efeitos de rede impulsionam a adoção maciça dos usuários (Eisenmann, Parker, \& Van Alstyne, 2006; Parker et al., 2018).

Para conseguir construir esse ciclo virtuoso em um mercado de dois lados, pode fazer sentido subsidiar um lado para impulsionar a expansão e os ganhos do outro. Em geral, escolhe-se o lado mais sensível a preço para ser subsidiado.
Cupons de oferta são exemplos de subsídios para aumentar a rede (McAfee \& Brynjolfsson, 2017; Parker et al., 2018).

A mesma coisa ocorre com a Conexa entrando no B2C. Era necessário produzir efeitos de rede positivos e mitigar efeitos de rede negativos.

Para fazer crescer as redes de usuários e produzir efeitos de rede positivos, a Conexa partiu de uma posição privilegiada, já que contava com uma rede de médicos credenciados na oferta $\mathrm{B} 2 \mathrm{~B}$ que passaram a atender também o segmento B2C. Além disso, como foi analisado, o cenário instaurado pelo COVID-19 fortaleceu efeitos de rede, tanto do lado dos médicos (que passaram a preferir atendimentos remotos e/ou buscavam novas fontes de receita) quanto do lado dos pacientes de classe $\mathrm{C}$ (que também buscavam atendimentos remotos com preços acessíveis). Para impulsionar ainda mais o lado dos pacientes, a empresa praticou um preço promocional, descomplicou a adesão ao implementar o pagamento com cartão de crédito, utilizou táticas de marketing digital e implementou parcerias com novos canais de vendas e divulgação. Um desafio com relação ao público-alvo escolhido pela Conexa (classe $\mathrm{C}$, sem plano de saúde) é que a empresa não lidava com esse público anteriormente e, com a entrada abrupta no mercado, provavelmente mais pesquisas sobre a jornada desse tipo de paciente serão necessárias.

No intuito de mitigar efeitos de rede negativos, a Conexa tomou providências para se precaver de problemas relacionados ao crescimento rápido, implementando uma curadoria de qualidade que promovesse pareamentos de valor para os usuários. Nesse caso, os médicos passavam por um processo seletivo semelhante ao de um plantáo físico. A empresa também implementou protocolos de atendimento 
baseados em algoritmos reconhecidos em sociedades médicas. Adicionalmente, os atendimentos são avaliados pelo paciente por meio de Net Promoter Score (NPS) e este atribui notas aos médicos. Toda vez que um paciente vai escolher o médico para o atendimento, ele tem acesso ao currículo do médico e à nota média de seus atendimentos. Uma questão que afeta negativamente a percepção do atendimento e que permanece sem solução é a má qualidade do acesso à internet por parte dos pacientes.

Questão 3: Quais são os desafios pós-COVID em relação ao ambiente competitivo da telemedicina no Brasil?

O objetivo dessa questão é permitir ao professor explorar a compreensão da dinâmica competitiva em um ecossistema de plataforma. Espera-se que a discussão faça emergir aspectos tais como:

- Maior demanda dos consumidores e médicos adaptados à telemedicina (+).

- Risco de um crescimento acelerado do setor náo ser acompanhado de qualidade do serviço (-).

- Ameaça de retorno da barreira legal com suspensão de regulamentaçóes (-).

- Ameaça de outras questôes regulatórias que incluam acesso, compatibilidade, precificação justa, privacidade e segurança dos dados, controle nacional sobre recursos de informação, política tributária e legislação trabalhista (-).

- Entrada de novos competidores de origens variadas como, por exemplo: seguradoras de saúde, hospitais, plataformas globais, plataformas de outros setores, tais como: gigantes da tecnologia e plataformas de educação a distância (-).

- Entrada de novos parceiros com complementos às soluçóes das plataformas (+).

- Aprimoramento das iniciativas de telemedicina com incorporação dos aprendizados adquiridos durante a pandemia $(+)$.

- Estratégias omnichannel para cobrir a jornada do paciente, com integração de ofertas mediante parcerias e/ou aquisiçóes inclusive com empresas de diferentes setores, como varejo, delivery, entre outros $(+)$.

- Maior variedade dos serviços de saúde, não se restringindo a simular remotamente as consultas médicas que existiam no canal presencial $(+)$.

- Desenvolvimento de devices e soluçóes que permitam expandir a telemedicina para novas especialidades $(+)$.

O professor pode listar os tópicos levantados pelos alunos para finalizar o quadro comparativo - ver Lâmina 4 do plano de discussão plenária (Apêndice).
O modelo de negócios baseado em plataforma muda a própria natureza da competição, já que há um dinamismo constante entre as atuaçôes das empresas, que torna as vantagens estratégicas bastante efêmeras. A simples posse da infraestrutura náo assegura uma fonte de valor perene, mas sim a aproximaçáo com o consumidor e a flexibilidade para criar, reconfigurar, aumentar e capturar valor no ecossistema de diferentes formas ao longo do tempo. Essa flexibilidade advém do fato de que as plataformas podem aproveitar as oportunidades de mercado diretamente ou via parcerias que, muitas vezes, mudam as características do ecossistema. Geralmente, as plataformas tentarão buscar diretamente as oportunidades mais atrativas, deixando parceiros desenvolverem as mais periféricas e compartilharem o valor produzido. Porém, as plataformas monitoram continuamente o ambiente competitivo e podem partir para aquisiçóes ou parcerias inusitadas (Parker et al., 2018).

TQ 3.1: Olhando para os desafios que vocês listaram no pósCOVID, quem serão os potenciais novos entrantes? Como o ambiente competitivo poderá se modificar?

O professor pode usar as contribuiçóes dos alunos para completar a visão do ecossistema com novos entrantes, parceiros ou ofertas - ver Lâminas 4 e 5.

TQ 3.2: Se você (aluno) fosse gestor da Conexa, como atuaria para aproveitar as oportunidades que surgem nesse ecossistema? Que tipo de relaçóes estabeleceria com os demais participantes? Onde tentaria atuar diretamente e onde estabeleceria parcerias?

O esquema completo do ecossistema evidenciará uma maior complexidade na competição. Novas plataformas e novos parceiros adentram o ecossistema, trazendo consigo outras oportunidades de interaçóes e criação de valor, assim como três formas distintas de concorrência: plataforma contra plataforma, plataforma contra parceiro e parceiro contra parceiro.

$\mathrm{Na}$ concorrência entre plataformas, é provável que, caso a regulamentação se mantenha favorável à telemedicina após a pandemia, ocorra um acirramento da competiçáo pela entrada de outras plataformas, que podem ter origem em diferentes setores econômicos. Terão vantagem estratégica aquelas plataformas com maior poder no ecossistema como um todo e maior proximidade com seus usuários. A Conexa se orgulha de ser uma plataforma independente. Essa pode ser uma força por abrir um leque de possibilidades de parceria e, portanto, extrema flexibilidade na forma de atuar. Por outro lado, outras empresas podem acumular mais dados sobre seus pacientes em momentos distintos da teleconsulta, seja durante sua jornada em outros serviços de saúde (consultas de especialistas, hospitais, exames, etc.), seja em outros momentos como quando os pacientes estáo comprando, navegando pela internet ou usando equipamentos de monitoramento 
(ex.: relógio da Apple). É preciso monitorar esse cenário a fim de compreender onde estão as oportunidades de unir esforços com outras plataformas e parceiros. Serviços de saúde não convencionais, novas interaçóes que gerem conhecimento sobre o consumidor em momentos distintos (ex.: interaçóes entre pacientes), atuação em novas especialidades viabilizada por devices e softwares que favoreçam o exame clínico, integração de funcionalidades e/ou modalidades que permitam ao paciente uma experiência omnichannel (sem fricção entre os canais), enfim, todas essas são oportunidades de atuação direta ou, principalmente, de parcerias.

A concorrência da plataforma com seus parceiros pode ser exemplificada com o Marketplace da Amazon. Nessa situação, a Amazon vende seus produtos ao mesmo tempo que abre para seus parceiros venderem também. Esse é um movimento muito delicado e, embora possa ter ganhos no curto prazo para a plataforma, pode enfraquecer seus parceiros. Quando a Conexa oferece teleconsulta mirando em pacientes de classe $\mathrm{C}$ sem plano de saúde, pode esbarrar no futuro em uma concorrência com seguradoras parceiras que queiram expandir seus portfólios de oferta para esse segmento via telemedicina. Para mitigar esse risco, a Conexa tomou algumas providências, tais como: ser bem transparente com os parceiros em relaçáo ao movimento e criar marca e estruturas independentes. No entanto, talvez a empresa precise pensar em possíveis consequências no caso de essas medidas não serem suficientes. Haveria algum valor a ser compartilhado em uma possível parceria? Para refletir sobre essa questão, é preciso ter em mente que os parceiros podem desempenhar distintos e múltiplos papéis ao longo do tempo.

O último tipo de concorrência se refere aos parceiros que disputam entre si os mesmos clientes.

À medida que a Conexa vai expandindo sua atuação no ecossistema, aumentando suas parcerias, precisa estar atenta aos valores criados e compartilhados com seus parceiros, fazendo com que as parcerias se mantenham vantajosas para ambos os lados, tendo como perspectiva comparativa todos os parceiros do ecossistema. Parceiros de criação de valor são preciosos.

O professor pode pedir que levantem a mão os alunos que acharem que o ecossistema pós-COVID-19 favorece oportunidades de valor que a Conexa deve aproveitar diretamente, de forma isolada. Em seguida, pedir para levantarem a mão aqueles que acham que o ecossistema está oferecendo maior potencial de (co)criação de valor por meio de parcerias. Pedir a contribuição de alguns alunos justificando sua escolha.
A ideia é que os alunos percebam que o favorecimento das plataformas à colaboração e à cocriação torna a simples competição menos relevante. Nesse momento, pode ser introduzido o termo 'coopetiçáo' dos autores Barry Nalebuff, Adam Brandenburger e Agus Maulana, que nos esclarecem que "em mercados de plataforma, uma estratégia vencedora obscurece os limites entre participantes do mercado, aumentando assim as interações valiosas no ecossistema" (Parker et al., 2018, p. 227).

As plataformas competem de forma muito diferente das empresas tradicionais e não se encaixam em teorias clássicas de estratégia, como o modelo das cinco forças de Porter ou a visão baseada em recursos (RBV). A competiçâao das plataformas envolve outros aspectos, tais como: limitação do acesso à participação em um ecossistema; busca por inovaçóes e (co)criação de valor; alavancagem do uso e monetização dos dados; reconfiguraçóes do mercado em termos de fusóes, aquisiçóes e parcerias; envelopamento da plataforma ao incluir funcionalidades melhores que as de outros competidores; e aperfeiçoamento do design e da experiência do usuário.

Nesse momento, o professor pode optar por detalhar um ou mais desses aspectos.

\section{Encerramento da discussão}

O encerramento poderia ser usado para refletir sobre o dilema apresentado pelos protagonistas. O caso se encerra com eles preocupados com um possível retorno da legislação, voltando a proibir o teleatendimento. Nesse momento, o professor poderia repassar os aprendizados nos esquemas propostos para o quadro (conceito de plataforma, efeitos de rede e dinâmica competitiva nos mercados de plataforma) e abrir a discussão sobre uma das características dos empreendedores: a tomada de risco. Caso plataformas $\mathrm{B} 2 \mathrm{C}$ não pudessem mais operar, o que os sócios poderiam fazer com a Docpass e os aprendizados acumulados? Toda a jornada de criação da empresa poderia servir para alavancar os negócios anteriores e/ou novos? Que parcerias poderiam ser promissoras? A resposta a essas perguntas evidencia a importância do diagnóstico feito durante a discussão do caso sobre como plataformas operam em ambiente de redes e coopetição. Com a experiência da Docpass, a Conexa se torna ainda mais preparada para atuar em novas realidades. As empresas operam em contextos de variaçóes constantes do ambiente externo, gerando alta incerteza; assim, a tomada de risco é uma característica recorrente nas decisóes dos empreendedores. 


\section{REFERÊNCIAS}

Eisenmann, T., Parker, G., \& Van Alstyne M. W. (2006). Strategies for two-sided markets. Harvard Business Review, 84(10), 92. Retrieved from https://hbr.org/2006/10/strategies-for-two-sided-markets

Hagiu (2014). Strategic decisions for multisided platforms. MIT Sloan Management Review, 55, 71-80. Retrieved from https://www.hbs.edu/faculty/Pages/item.aspx?num=46062

McAfee, A., \& Brynjolfsson, E. (2017) Machine, platform, crowd: Harnessing our digital future. New York: Norton \& Company.

\section{Autoria}

\section{Catia Silva da Costa Moreira*}

Universidade Federal Fluminense, Faculdade de Administraçáo e Ciências Contábeis, Departamento de Empreendedorismo

Rua Mário Santos Braga, s/n, Prédio 1, $7^{\circ}$ Andar, Centro, 24220-

900, Niterói, RJ, Brasil

E-mail: catia.moreira@coppead.ufrj.br

(D) https://orcid.org/0000-0003-3969-6693

\section{Flavia D'Albergaria Freitas}

Universidade Federal do Rio de Janeiro, Instituto COPPEAD de Administração

Rua Pascoal Lemme, no 355, Cidade Universitária, 21941-918, Rio de Janeiro, RJ, Brasil

E-mail: flaviadaf@gmail.com

(D) https://orcid.org/0000-0003-4870-2864

\section{Carolina Brandão}

Pontifícia Universidade Católica do Rio de Janeiro

Rua Marquês de Sáo Vicente, no 225, Gávea, 22541-041, Rio de Janeiro, RJ, Brasil

E-mail: carolina.brandao@coppead.ufrj.br

(D) https://orcid.org/0000-0003-0294-8893

\section{Cláudia Affonso Silva Araujo}

Universidade Federal do Rio de Janeiro, Instituto COPPEAD de Administração

Rua Pascoal Lemme, no 355, Cidade Universitária, 21941-918, Rio de Janeiro, RJ, Brasil

Fundação Getulio Vargas, Escola de Administração de Empresas de São Paulo

Av. 9 de julho, no 2029, Bela Vista, 01313-902, São Paulo, SP, Brasil

E-mail: claraujo@coppead.ufrj.br

(D) https://orcid.org/0000-0003-0290-4807

* Autora Correspondente

\section{Direitos Autorais}

A RAC detém os direitos autorais deste conteúdo.

\section{Conflito de Interesses}

Os autores informaram que não há conflito de interesses.
Parker, G., Van Alstyne, M. W., \& Choudary, S. (2018). Plataforma a reevolução da estratégia: O que é a plataforma de negócios, como surgiu e como transforma a economia em alta velocidade. Rio de Janeiro: Alta books.

Shapiro \& Varian (2003). A economia da informação. Rio de Janeiro: Elsevier.

Tiwana (2013). Platform ecosystems: Aligning architecture, governance, and strategy. Burlington, MA: Morgan Kaufmann.

\section{Contribuições dos Autores}

$1^{a}$ autora: conceitualização (líder); curadoria de dados (líder); análise formal (igual); investigação (líder); redação rascunho original (igual); metodologia (igual).

2a autora: conceitualização (apoio); curadoria de dados (apoio); análise formal (igual); metodologia (igual); redação - rascunho original (igual).

$3^{\text {a }}$ autora: investigação (apoio); conceitualização (apoio); curadoria de dados (apoio); redação - rascunho original (apoio).

$4^{\text {a }}$ autora: conceitualizaçáo (apoio); investigação (apoio); metodologia (apoio); redação - rascunho original (apoio); redação - revisão e edição (líder).

\section{Financiamento}

As autoras relataram que não houve suporte financeiro para a pesquisa deste artigo.

\section{Verificação de Plágio}

A RAC mantém a prática de submeter todos os documentos aprovados para publicação à verificação de plágio, mediante o emprego de ferramentas específicas, e.g.: iThenticate.

\section{Método de Revisão por Pares}

Este conteúdo foi avaliado utilizando o processo de revisão por pares duplo-cego (double-blind peer-review). A divulgação das informaçôes dos pareceristas constantes na primeira página é feita somente após a conclusão do processo avaliativo, e com o consentimento voluntário dos respectivos pareceristas.

\section{Disponibilidade dos Dados}

A RAC incentiva o compartilhamento de dados mas, por observância a ditames éticos, não demanda a divulgaçáo de qualquer meio de identificação de sujeitos de pesquisa, preservando a privacidade dos sujeitos de pesquisa. A prática de open data é viabilizar a reproducibilidade de resultados, e assegurar a irrestrita transparência dos resultados da pesquisa publicada, sem que seja demandada a identidade de sujeitos de pesquisa. 


\section{APÊNDICE A}

\section{Pré-COVID}

Cenário da Telemedicina:

- Tecnologia disponível (+)

- Barreira cultural (-)

- Baixa capacitação tecnológica dos usuários (-)

- Usuários já estavam mais familiarizados com tecnologia $(+)$

- Tentativa de regulamentação em 2019 falha por resistência e protestos da classe médica $(-)$

\section{Ofertas da Conexa}

- Software as a service - Saas

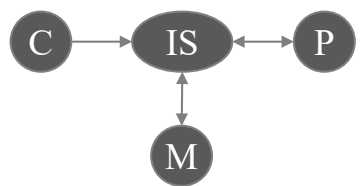

- Teleconsultas (B2B)

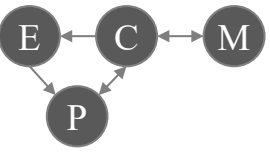

\section{Durante a COVID}

\section{Cenário da Telemedicina:}

- Cuidado remoto oferecia vantagens. $(+)$

- Pacientes com outras doenças: não se expor aos riscos $(+)$

- Serviços de saúde acima de sua capacidade $(+)$

- Opção para médicos gerarem receitas $(+)$

- Nova regulamentação $(+)$

- Planos de saúde remunerando teleatendimento (+)

- Maior uso de plataformas em geral (+)

- Algumas especialidades limitadas pelas características dos exames físicos necessários (-)

- Players com diferentes graus de maturidade. (+-)

\section{Ofertas da Conexa \\ - Docpass}

\section{P}

Atendidos rapidamente

Conveniência

Qualidade

Buscar pacientes

Preço promocional

Meios de pagamento

Marketing digital

Parcerias
Efeitos de Rede NPS

Curadoria de médicos Protocolos de atendimento

3

\section{Pós-COVID}

\section{Cenário da Telemedicina:}

- Maior demanda dos consumidores e médicos possivelmente adaptados à telemedicina $(+)$

- Risco de crescimento acelerado afetar a qualidade do serviço (-)

- Risco de retorno da barreira legal com suspensão de regulamentações (-)

- Ameaça de outras questões regulatórias (-)

- Entrada de novos competidores de origens variadas (-)

- Entrada de novos parceiros com complementos às soluções das plataformas $(+)$

- Aprimoramento das iniciativas de telemedicina $(+)$

- Estratégias omnichannel (+)

- Maior variedade dos serviços de saúde (+)

- Desenvolvimento de devices e soluções que permitam expandir a telemedicina para novas especialidades $(+)$

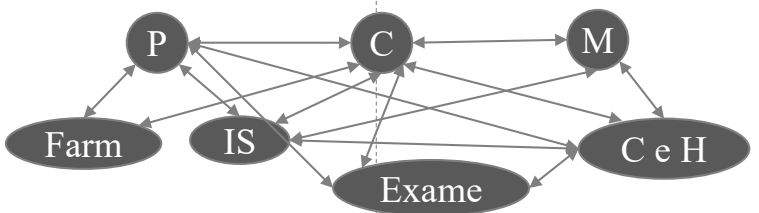

\section{“Coopetição" de Plataforma}

- Limitação do acesso

- Estímulo à inovação e captura de valor

- Alavancagem do valor dos dados
- Redefinição de fusões e aquisições

- Envelopamento da Plataforma

- Aperfeiçoamento do Design

- Vantagem Sustentada

Figura A1. Plano de discussão plenária (esquema proposto para o quadro).

Fonte: Elaborado pelos autores. 